\title{
Are gait parameters altered in adults with hallux valgus?
}

\author{
Sheree Nix ${ }^{1,2^{*}}$, Bill Vicenzino ${ }^{1}$, Natalie Collins ${ }^{3,4}$, Michelle Smith ${ }^{1}$ \\ From Australasian Podiatry Council Conference 2013 \\ Sydney, Australia. 2-5 June 2013
}

\section{Background}

Gait parameters such as excessive pronation have been suggested as contributing to the development of hallux valgus (HV). HV has also been linked to functional disability in older adults. However, the literature investigating gait parameters in $\mathrm{HV}$ has not previously been systematically evaluated.

\section{Methods}

A systematic review was conducted, searching electronic databases to October 2011. Cross-sectional studies with clearly defined HV and non-HV groups were included. Two investigators rated papers for methodological quality. Effect sizes (95\% confidence intervals (CI)) were calculated as standardized mean differences (SMD) for continuous data and risk ratios (RR) for dichotomous data.

\section{Results}

Nine papers were included (total $n=589$ ). One study showed that during terminal stance HV participants had reduced ankle dorsiflexion $(\mathrm{SMD}=-0.81, \mathrm{CI}:-1.44$ to -0.18 ) and less rearfoot supination (SMD $=-0.63,-1.25$ to -0.01) compared to controls. In another study HV participants showed early onset of intrinsic muscle activity (RR 1.6, 1.1 to 2.2). Four studies investigating spatiotemporal parameters found no significant differences between groups, although one study found reduced speed (SMD -0.73), step length (SMD -0.66 to -0.59) and less stable gait patterns (SMD -0.86 to -0.78 ) in older adults with moderate to severe HV. Six studies investigated plantar pressures with inconsistent findings.

\footnotetext{
* Correspondence: s.nix@qut.edu.au

'School of Health and Rehabilitation Sciences, The University of Queensland, Brisbane, QLD, 4072, Australia

Full list of author information is available at the end of the article
}

\section{Conclusion}

Altered gait kinematics and muscle activity are apparent in $\mathrm{HV}$, and these parameters warrant further investigation. Although conclusions regarding causality cannot be drawn from cross-sectional studies, interventions targeting these parameters may improve clinical outcomes in $\mathrm{HV}$.

\section{Author details}

${ }^{1}$ School of Health and Rehabilitation Sciences, The University of Queensland, Brisbane, QLD, 4072, Australia. ${ }^{2}$ School of Clinical Sciences, Queensland University of Technology, Brisbane, QLD, 4059, Australia. ${ }^{3}$ Department of Mechanical Engineering, The University of Melbourne, Melbourne, VIC, 3010, Australia. ${ }^{4}$ Department of Physiotherapy, The University of Melbourne, Melbourne, VIC, 3010, Australia.

Published: 31 May 2013

doi:10.1186/1757-1146-6-S1-O29

Cite this article as: Nix et al:: Are gait parameters altered in adults with hallux valgus? Journal of Foot and Ankle Research 2013 6(Suppl 1):029.

Submit your next manuscript to BioMed Central and take full advantage of:

- Convenient online submission

- Thorough peer review

- No space constraints or color figure charges

- Immediate publication on acceptance

- Inclusion in PubMed, CAS, Scopus and Google Scholar

- Research which is freely available for redistribution

Submit your manuscript at www.biomedcentral.com/submit
() Biomed Central

\section{Biomed Central}

